\title{
Efektifitas Latihan Range Of Motion (ROM) Aktif terhadap Tonus Otot Ekstrimitas bawah dan Rentang Gerak Sendi pada Lansia
}

\author{
Nindawi $^{1}$, Endang Fauziyah Susilawati ${ }^{2}$, Nur Iszakiyah ${ }^{3}$ \\ 1,2,3 Jurusan Kesehatan Politeknik Negeri Madura \\ nindawi70@gmail.com*, ${ }^{2}$ endangfauziyah.nawawi@gmail.com. ${ }^{3}$ izsakiyahnur@gmail.com \\ *Corresponding Author
}

\begin{tabular}{l}
\hline Informasi artikel \\
\hline Sejarah artikel: \\
Received: 17-02-2021 \\
Revised: 07-04-2021 \\
Accepted: 31-05-2021 \\
\hline Kata kunci: \\
Range Of Motion (ROM) \\
aktif, \\
Rentang Gerak Sendi, \\
Kekuatan otot kaki, Lanjut \\
Usia.
\end{tabular}

ABSTRAK
Masalah kesehatan pada Lansia dapat terjadi pada beberapa bagian tubuh
termasuk sistem muskuloskletal antara lain persendian dan kekuatan
otot. Perubahan yang biasa terjadi adalah penurunan elastisitas pada
jaringan ikat sekitar sendi seperti ligamen, tendon, dan fasia. Latihan ROM
merupakan salah satu bentuk latihan dalam proses rehabilitasi yang
dinilai masih sangat efektif. Penelitian ini bertujuan untuk menganalisa
pengaruh latihan ROM aktif terhadap peningkatan rentang gerak sendi
dan kekuatan otot kaki pada lansia di wilayah kerja Puskesmas Kowel
Pamekasan. Penelitian kuantitatif, dengan desain pre eksperimen pre dan
post test design group. Teknik pengambilan sampel non probability
purposive sampling dan sampel 30 orang. Data diperoleh melalui
observasi awal dan akhir luas rentang gerak sendi dan kekuatan otot kaki
yang diberikan latihan ROM aktif selama 2 minggu. Analisis statistiknya
univariat dengan uji distribusi frekuensi dan bivariate dengan paired $t$
test. Hasil penelitian didapatkan peningkatan rentang gerak sendi kaki
pada Lansia yaitu lutut fleksi-ekstensi rata-rata meningkat $4,57^{\circ} p$ value
0,000, ankle plantar fleksi rata-rata meningkat $4.53^{\circ} p$ value 0,000 , ankle
dorsal fleksi rata-rata meningkat $2.27^{0} p$ value 0,000 , dan rata-rata
meningkat 0,76 untuk kekuatan otot tungkai $p$ value $0,000(<0,05)$, artinya
terdapat pengauh latihan ROM aktif terhadap rentang gerak sendi kaki
dan kekuatan otot pada Lansia. Latihan ROM yang dilakukan sedini
mungkin dan dilakukan dengan benar dan secara terus menerus akan
memberikan dampak pada kekuatan otot dan rentang gerak sendi. Di
masa yang akan datang, kelompok lansia memerlukan pendidikan
kesehatan dan pendampingan yang baik agar bisa melakukan latihan ROM
di rumah secara rutin dan berkelanjutan.

Key word:

Active Range Of Motion (ROM),

Leg muscle strength, Elderly.
Range of Motion,

\section{ABSTRACT}

Health problems in the elderly can occur in several parts of the body including the musculoskletal system, including joints and muscle strength. Changes in connective tissue around joints such as tendons, ligaments, and fascia that experience decreased elasticity. ROM exercise is a form of training in the rehabilitation process which is still considered very effective. This study aims to analyze the effect of active ROM training on the increase in range of motion and leg muscle strength in the elderly in the working area of Puskesmas Kowel Pamekasan. Quantitative research, with preexperimental design pre and post test group design. The sampling technique was non-probability purposive sampling and a sample of 30 people. Data were obtained through early and late observation of the range of motion of the joints and leg muscle strength that were given active ROM exercises for 2 weeks. Univariate statistical analysis with frequency distribution test and bivariate with paired t test. The results showed an increase in the range of motion of the leg joints in the elderly, namely knee flexion-extension on average increased by $4.570 p$ value 0.000 , ankle plantar flexion on average increased by 4.530 p value 0.000, ankle dorsal flexion on average increased by $2.270 p$ value 0.000 , and average-Average increase of 0.76 for leg muscle strength $p$ value 0.000 (<0.05), meaning that there is an effect of active ROM training on the range of motion of the 
leg joints and muscle strength in the elderly. ROM exercises that are done as early as possible and done correctly and continuously will have an impact on muscle strength and range of motion.

\section{Pendahuluan}

Proses menua adalah hilangnya kemampuan jaringan untuk memperbaiki diri/mengganti dan mempertahankan fungsi normalnya secara perlahan-lahan sehingga rentan terhadap infeksi dan kemampuan memperbaiki kerusakan yag terjadi. Penuaan menyebabkan penurunan kekuatan otot dan fleksibilitas sendi kaki pada lansia. Hal ini juga dipengaruhi berkurangnya pergerakan dan pemakaian sendi serta minimnya aktifitas fisik pada lansia. Masalah-masalah kesehatan pada lansia terjadi pada berbagai sistem tubuh khususnya sistem muskuloskeletal. Jenis penyakit pada sistem muskuloskeletal yang paling umum adalah rematik dengan Osteoarthritis (Nainggolan, 2009)

Menurut Hetty Antje Geru, Lansia merupakan tahapan akhir. perjalanan hidup manusia dari fase kehidupannya (Hetty, 2020). Saat ini piramida penduduk semakin melebar di atas, dengan kata lain kelompok umur lansia semankin banyak. Jumlah lansia di indonesia pada 2019 berkisar $10 \%$ atau sekitar 26 juta orang dari jumlah seluruh penduduk indonesia. Secara matematis akan menjadi sebanyak 48 juta orang $(15,77 \%)$ pada tahun 2035. Usia harapan hidup kelompok lansia juga bertambah, bukan hanya bertambah dalam jumlah. WHO mengelompokkan lansia menjadi middle age (45-59 tahun), elderly (60-74 tahun), old (75-90 tahun), dan very old (>90 tahun). Kemenkes indonesia membagi menjadi pra-lansia (45-59 tahun) dan lansia berusia 60 tahun atau lebih.

Berdasarkan perubahan epidemiologis, penyakit pada lanjut usia cenderung ke arah penyakit degeneratif (Helmi, 2012). Di Indonesia, pada tahun 2000 jumlah lanjut usia di Indonesia terdapat 22,3 juta jiwa dengan umur harapan hidup 65-75 tahun dan diperkirakan pada tahun 2020 akan meningkat menjadi $11,09 \%(29,12$ juta lebih) dengan usia harapan hidup 70-75 tahun (Ayu \& Warsito B. E, 2014). Menurut WHO, gangguan sendi yang sering terjadi di Indonesia seperti terkilir, dislokasi, ankilosis dan artritis mencapai 81\% dari total populasi, sebagian kecil pergi ke dokter, sekitar 70\% memilih mengkonsumsi obat-obatan pereda nyeri yang dijual bebas.
Pada hasil survey di Wilayah Kerja Puskesmas Kowel Pamekasan 2020, jumlah 72 lansia (45 wanita dan 27 laki-laki). Dari jumlah lansia yang ada, lebih dari 50\% mengalami masalah pada ekstrimitas bawah. Berdasarkan studi pendahuluan (survei awal) yang peneliti lakukan di Puskesmas Kowel pada bulan Agustus 2020 dengan mewawancarai 5 orang responden, 3 responden diantaranya menderita Osteoarthritis kurang lebih 4 tahun. Sedangkan terkait masalah otot yang terjadi, 4 responden mengatakan kaku dan nyeri pada persendian kakinya. Mereka mengalami keterbatasan rentang gerak terutama pada persendian ekstremitas bawah dan mempunyai kekuatan otot dibawah normal. Mereka mengatakan belum mengetahui tentang latihan ROM aktif. Sebagian hanya meelakukan senam. Para Lansia di Puskesmas Kowel mengikuti senam 1 minggu sekali.

Lanjut usia sering identik dengan produktifitas yang menurun karena kurang produktif. Secara fisiologis lansia, fungsifungsi tubuhnya menurun mengakibatkan rentan mengalami masalah kesehatan. Massa otot lansia mengalami atropi dan fleksibilitasnya mempengaruhi aktifitas lansia. Aktifitas gerak otot menyebabkan kekuatan otot menurun (Ambartana, 2010). Pada lansia terjadi penurunan tonus otot dan penipisan kartilago sendi, ligamen menjadi kaku (fleksibilitas), sehingga pergerakan menurun(Uliya et al., 2007). Pada lansia serat otot akan mengecil dan massa otot akan berkurang terutama saat kondisi istirahat dan imobilitas sepenuhnya (Stanley \& Beare, 2006). Hal tersebut menjadi semakin parah jika terdapat penurunan. pergerakan dan aktifitas pemakaian sendi (Suhendriyo, 2014).

Oleh karena itu, diperlukan adanya penanganan lebih lanjut terkait masalah penurunan fungsi ekstrimitas pada lansia. Terapi non farmakologi diantaranya adalah fisioterapi, mengatasi masalah nyeri meningkatkan tanus otot. Latihan gerak aktif merupakan salah satu cara mengelola kondisi tubuh terkait dengan fungsi pergerakan. Latihan gerak aktif dapat diartikan latihan yang memungkinkan agar persendian dapat bergerak tanpa merasakan sakit. Dengan melakukan kedua 
latihan ini maka dapat meningkatkan fleksibilitas.

\section{METODE PENELITIAN}

Metode kuantitatif Pre Eksperimen dengan desain penelitian One Group PrePost Test Design. Penelitian ini menggunakan lembar observasi sebagai instrumen penelitian dan alat untuk mengukur ROM yaitu Goniometer serta menggunakan skala kekuatan otot menurut Reeves. Setiap responden mulai dari prepost test dilakukan selama 2 minggu dengan latihan ROM aktif pada area lutuk fleksi ekstensi, ankle plantar fleksi dan ankle dorsofleksi, dan kekuatan otot dengan hitungan sampai 8 dan diulangi setiap gerakan sebanyak 4 kali, dengan frekuensi 5 kali dalam sehari. Variabel penelitian ini meliputi variabel independen sebagai variabel perlakuan yaitu latihan range of motion (gerakan lutut fleksi ekstensi, ankle gerakan plantar fleksi dan ankle dorso feksi), sedangkan variabel dependennya adalah pre test (rentang gerak sendi lutut dan ankle)-kekuatan otot kaki dan post test (rentang gerak sendi lutut dan ankle)-kekuatan otot kaki pada Lansia.Populasi dalam penelitian ini adalah semua lansia penderita osteoarthritis yang tercatat di Puskesmas Kowel Pamekasan pada yahun 2021 sebanyak 267 orang, sedangkan di wilayah kerja Puskesmas Pembantu Bugih tercatat 72 lansia. Teknik non probability of Purposive Sampling ditemukan 30 responden, dengan kriteria inklusif: 1). Lansia yang tidak sedang mengalami nyeri osteoarthritis 2). Mengalami osteoarthritis dengan tonus otot $\leq 4$. Tujuan penelitian ini mengetahui pengaruh latihan gerak aktif (Range of Motion) terhadap rentang gerak sendi dan kekuatan otot kaki pada lansia. Analisa data menggunakan teknik analisis univariat dan bivariat dengan menggunakan uji $\mathrm{T}$ Dependen.

\section{HASIL DAN PEMBAHASAN}

Tabel 1 Usia Responden

\begin{tabular}{cccc}
\hline No & \multicolumn{1}{c}{ Usia } & f & $\%$ \\
\hline 1 & $60-65$ & 12 & 40.0 \\
\hline 2 & $66-71$ & 6 & 20.0 \\
\hline 3 & $72-79$ & 8 & 26.7 \\
\hline 4 & $80-92$ & 4 & 13.3 \\
\hline & Jumlah & 30 & 100 \\
\hline
\end{tabular}

Sumber : Data Primer 2020
Berdasarkan tabel 1 diapatkan hasil bahwa hampir setengahnya responden berusia 6065 tahun sebanyak 12 orang (40\%).

Tabel 2 Jenis Kelamin Responden

\begin{tabular}{clcc}
\hline No & Jenis Kelamin & F & $\%$ \\
\hline 1 & Laki-laki & 4 & 13.3 \\
\hline 2 & Perempuan & 26 & 86.7 \\
\hline & Jumlah & 30 & 100
\end{tabular}

Sumber : Data Primer 2020

Berdasarkan tabel 2 didapatkan hasil bahwa hampir seluruhnya responden dengan jenis kelamin perempuan sebanyak 26 orang $(86,7 \%)$.

Tabel 3 Rentang Gerak Sendi Lutut FleksiEsktensi

\begin{tabular}{clcccc}
\hline No & $\begin{array}{l}\text { Luas } \\
\text { rentang } \\
\text { gerak }\end{array}$ & \multicolumn{2}{c}{ Pre Test } & \multicolumn{2}{c}{ Post Test } \\
\cline { 2 - 6 } & $\mathrm{f}$ & $\mathrm{f}$ & $\mathrm{f}$ \\
\hline 1 & Baik & 4 & 13.3 & 11 & 36.7 \\
\hline 2 & Cukup & 10 & 33.3 & 17 & 56.7 \\
\hline 3 & Kurang & 16 & 53.3 & 2 & 6.7 \\
\hline & Jumlah & 30 & 100.0 & 30 & 100.0 \\
\hline
\end{tabular}

Sumber : Data Primer 2020

Berdasarkan tabel 3 didapatkan hasil bahwa sebagian besar responden Luas Gerak Sendi lutut fleksi-ekstensi sebelum dilakukan latihan ROM aktif dengan kategori kurang sebanyak 16 orang $(53,3 \%)$ rata-rata $119,87^{\circ}$ dan sebagian besar responden Luas Gerak Sendi lutut fleksiekstensi sesudah dilakukan latihan ROM aktif dengan kategori cukup sebanyak 17 orang $(56,7 \%)$ rata-rata $124,43^{\circ}$ di Wilayah Kerja Puskesmas Kowel Pamekasan 2020

Tabel 4 Rentang Gerak Sendi Ankle Plantar Fleksi

\begin{tabular}{clcccc}
\hline No & $\begin{array}{l}\text { Luas } \\
\text { rentang } \\
\text { gerak }\end{array}$ & $\mathrm{f}$ & $\%$ & $\mathrm{f}$ & $\%$ \\
\cline { 2 - 6 } & Baik & 7 & $\%$ & 17 & 56.7 \\
\hline 2 & Cukup & 10 & 23.3 & 13 & 43.3 \\
\hline 3 & Kurang & 13 & 33.3 & 0 & 0,0 \\
\hline & Jumlah & 30 & 43.3 & 30 & 100.0 \\
\hline
\end{tabular}

Sumber : Data Primer 2020

Berdasarkan tabel 4 didapatkan hasil bahwa hampir setengahnya responden rentang gerak sendi ankle kaki gerakan plantar fleksi responden sebelum dilakukan latihan ROM aktif dengan kategori kurang sebanyak 13 orang $(43,3 \%)$ rata-rata $44.30^{\circ}$, dan sebagian besar responden rentang gerak sendi ankle kaki gerakan plantar fleksi responden sesudah dilakukan latihan 
ROM aktif dengan kategori baik sebanyak 17 orang $(56,7 \%)$ rata-rata $48.83^{\circ}$ (cukup)

Tabel 5 Luas Rentang Gerak Sendi Ankle Dorso Fleksi

\begin{tabular}{llcccc}
\hline No & $\begin{array}{l}\text { Luas } \\
\text { rentang } \\
\text { gerak }\end{array}$ & \multicolumn{2}{c}{ Pre Test } & \multicolumn{2}{c}{ Post Test } \\
\cline { 2 - 6 } & $\mathrm{f}$ & $\%$ & $\mathrm{f}$ & $\%$ \\
\hline 1 & Baik & 9 & 30.0 & 23 & 76.7 \\
\hline 2 & Cukup & 16 & 53.3 & 7 & 23.3 \\
\hline 3 & Kurang & 5 & 16.7 & 0 & 0 \\
\hline & Jumlah & 30 & 100 & 30 & 100 \\
\hline
\end{tabular}

Sumber : Data Primer 2020

Berdasarkan tabel 5 didapatkan hasil bahwa sebagian besar responden rentang gerak sendi ankle kaki gerakan dorso fleksi responden sebelum dilakukan latihan ROM aktif dengan kategori cukup sebanyak 16 orang (54,3\%) rata-rata $17.20^{\circ}$ dan hampir seluruhnya responden rentang gerak sendi ankle kaki gerakan dorso fleksi responden sesudah dilakukan latihan ROM aktif dengan kategori baik sebanyak 23 orang (76,7 \%) rata-rata $19.46^{\circ}$ (cukup) di Wilayah Kerja Puskesmas Kowel Pamekasan 2020.

Tabel 6 Kekuatan Otot Kaki

\begin{tabular}{clcccc}
\hline No & $\begin{array}{c}\text { Kekuatan otot } \\
\text { sebelum }\end{array}$ & \multicolumn{2}{c}{ Pre Test } & \multicolumn{2}{c}{ Post Test } \\
\cline { 3 - 6 } & latihan ROM & $\mathrm{f}$ & $\%$ & $\mathrm{f}$ & $\%$ \\
\hline 1 & $($ zero $=0)$ & & & & \\
\hline 2 & $($ poor $=1)$ & & & & \\
\hline 3 & $($ trace $=2)$ & & & & \\
\hline 4 & $($ fair $=3)$ & 17 & 56.7 & 2 & 6.7 \\
\hline 5 & $($ good $=4)$ & 13 & 43.3 & 20 & 66.7 \\
\hline 6 & $($ normal $=5)$ & & & 8 & 26.7 \\
\hline & Jumlah & 30 & 100.0 & 30 & 100.0 \\
\hline
\end{tabular}

Sumber : Data Primer 2020

Berdasarkan tabel 6 didapatkan hasil bahwa hampir setengahnya responden kekuatan otot kaki sebelum dilakukan latihan ROM aktif dapat bergerak melawan gravitasi, ROM tidak komplit (fair $=3$ ) sebanyak 17 orang $(56,7 \%)$ dengan rata-rata 3,43 , dan sebagian besar responden kekuatan otot kaki sesudah dilakukan latihan ROM aktif yaitu ROM komplit terhadap gravitasi dengan beberapa resistensi (good $=4$ ) sebanyak 20 orang $(66,7 \%)$ dengan rata-rata 4,20 di Wilayah Kerja Puskesmas Kowel Pamekasan 2020

Tabel 7 Pengaruh Latihan Range Of Motion (ROM) Aktif terhadap Luas Gerak Sendi Lutut Fleksi-Esktensi

\begin{tabular}{llcc}
\hline $\begin{array}{c}\text { Luas gerak sendi } \\
\text { lutut kaki. }\end{array}$ & $\mathbf{n}$ & mean & $\begin{array}{c}P \\
\text { value }\end{array}$ \\
\hline $\begin{array}{l}\text { Luas gerak sendi lutut } \\
\text { Fleksi-Esktensi } \\
\text { sebelum dan sesudah }\end{array}$ & 30 & $-4,56667$ & 0,000 \\
ROM & & & \\
\hline $\begin{array}{c}\text { Sumber : Data Primer 2020 } \\
\text { Hasil penelitian }\end{array}$ & $\begin{array}{c}\text { yang } \\
\text { ROM }\end{array}$ & $\begin{array}{c}\text { telah } \\
\text { aktif, }\end{array}$ \\
dilakukan yaitu latihan & ROM
\end{tabular}

didapatkan rata-rata luas rentang gerak sendi lutut Fleksi-Esktensi sebelum intervensi $119,87^{\circ}$ dan sesudah intervensi sebesar $124,43^{\circ}$. Nilai rata-rata rentang gerak sendi lutut kaki sebelum dan sesudah latihan ROM sebesar $-4.57^{\circ}$, didapatkan $p$ value 0,000 ( $\mathrm{p}$ value $<0,05) \quad 0,000<0,05$ maka H0 ditolak, artinya terdapat pengaruh signifikan dari latihan ROM aktif terhadap rentang gerak sendi lutut kaki pada lansia

Tabel 8 Pengaruh ROM Aktif Terhadap Peningkatan Rentang Gerak Sendi Ankle (Plantar Fleksi).

Luas rentang gerak

sendi ankle kaki $\mathrm{n}$ mean $P$ (Plantar Fleksi) value

Luas rentang gerak

sendi ankle kaki $30 \quad-4.53 \quad 0,000$ sebelum dan

sesudah ROM

Sumber : Data Primer 2020

Pada pengukuran luas sendi ankle khususnya untuk gerakan plantar fleksi, didapatkan rata-rata luas rentang gerak sendi ankle (plantar fleksi) sebelum latihan ROM aktif adalah $44.30^{\circ}$ dan sesudah latihan ROM aktif sebesar $48.83^{\circ}$. Nilai ratarata rentang gerak sendi ankle (plantar fleksi) sebelum dan sesudah latihan ROM sebesar $-4.53^{\circ}$, didapatkan $\mathrm{p}$ value $0,000 \mathrm{(p}$ value < 0,05) 0,000 < 0,05 maka H0 ditolak, artinya terdapat pengaruh signifikan dari latihan ROM aktif terhadap peningkatan rentang gerak sendi ankle (plantar fleksi) pada lansia.

Tabel 9 Pengaruh ROM Aktif Terhadap Peningkatan Rentang Gerak Sendi Ankle (Dorso Fleksi).

Luas rentang

gerak sendi ankle $\quad \mathrm{n}$ mean $p$ kaki (Dorso n mean value Fleksi).

Luas rentang gerak sendi ankle kaki sebelum dan $30 \quad-2.26 \quad 0,000$ sesudah ROM

aktif

Sumber : Data Primer 2020 
Pada pengukuran luas sendi ankle khususnya untuk gerakan dorso fleksi, didapatkan rata-rata luas rentang gerak sendi ankle (dorso fleksi) sebelum latihan ROM aktif adalah $17.20^{\circ}$ dan sesudah latihan ROM aktif sebesar $19.46^{\circ}$. Nilai ratarata rentang gerak sendi ankle (dorso fleksi) sebelum dan sesudah latihan ROM sebesar $2.26^{\circ}$, didapatkan $\mathrm{p}$ value 0,000 ( $\mathrm{p}$ value $<0,05) \quad 0,000<0,05$ maka H0 ditolak, artinya terdapat pengaruh signifikan dari latihan ROM aktif terhadap peningkatan rentang gerak sendi ankle (dorso fleksi) pada lansia.

Tabel 10 Pengaruh ROM aktif terhadap kekuatan otot kaki

\begin{tabular}{|c|c|c|c|}
\hline Kekuatan otot & $\mathrm{n}$ & mean & Pvalue \\
\hline Kekuatan otot & & & \\
\hline $\begin{array}{ll}\text { kaki } & \text { sebelum } \\
\text { dan } & \text { sesudah } \\
\text { ROM } & \end{array}$ & 30 & $-0,76$ & 0,000 \\
\hline
\end{tabular}

Sumber : Data Primer 2020

Pada pengukuran kekuatan otok kaki, didapatkan rata-rata luas kekuatan otot kaki sebelum latihan ROM aktif adalah 3,43 dan sesudah latihan ROM aktif sebesar 4,20. Nilai rata-rata kekuatan otot kaki sebelum dan sesudah latihan ROM sebesar $-0,76$. Dengan demikian didapatkan $p$ value 0,000 ( $p$ value $<0,05$ ), maka H0 ditolak, artinya terdapat pengaruh signifikan dari latihan ROM aktif terhadap kekuatan otot kaki pada lansia.

\section{Pembahasan}

1. Rentang gerak sendi kaki (lutut fleksiesktensi, ankle plantar fleksi dan dorso fleksi) sebelum latihan ROM pada lansia.

Berdasarkan hasil penelitian ini didapatkan bahwa sebagian besar responden Luas Gerak Sendi lutut kaki gerakan fleksi-ekstensi sebelum dilakukan latihan ROM aktif dengan kategori kurang sebanyak 16 orang $(53,3 \%)$ dengan rata-rata $119,87^{\circ}$ masih di bawah $120^{\circ}$, hampir setengahnya responden rentang gerak sendi ankle kaki gerakan plantar fleksi dengan kategori kurang sebanyak 13 orang $(43,3 \%)$ dengan rata-rata $44,30^{\circ}$ masih di bawah $45^{\circ}$ , dan sebagian besar responden rentang gerak sendi ankle kaki gerakan dorso fleksi responden dengan kategori cukup sebanyak 16 orang $(54,3 \%)$ dengan rata-rata $17,20^{\circ}$ masih di bawah $20^{\circ}$ di Wilayah Kerja
Puskesmas Kowel Pamekasan 2020. Tendon, ligamen, fasia, kartilago dan jaringan ektrimitas lainnya mengalami kekakuan.

Lansian mengalami kalsifikasi dan mengurangi kelenturan jaringan pada sistem persendian (Uliya et al., 2007). Persendian, jaringan ikat dan tulang pada lansia mengalami degenerasi. sehingga elastisitas jaringan ikat dan tulang rawan berkurang sehingga mengalami penurunan fleksibilitas Selain itu perubahan elastisitas serabut otot menyebabkan jaringan ikat didalam serabut otot bertambah (Padila, 2013). Penyakit penyerta memperburuk kondisi masalah pada persendian. Sebagian besar lansia dalam penelitian ini memiliki penyakit penyerta yang berhubungan dengan penurunan kemampuan rentang gerak pada lansia seperti Remathoid Atritis dan Athritis Gout. (Sucipto, 2015). Pada lansia terjadi erosi, degenerasi, dan kalsifikasi pada kapsul sendi dan kartilago penurunan luas gerak sendi disebabkan sendi kehilangan fleksibilitasnya (Pudjiastuti \& Utomo, 2003).

\section{Rentang gerak sendi kaki (lutut fleksi- esktensi, ankle plantar fleksi dan dorso fleksi) sesudah latihan ROM pada lansia.}

Berdasarkan hasil penelitian ini didapatkan bahwa sebagian besar responden Luas Gerak Sendi lutut kaki gerakan fleksi-ekstensi sesudah dilakukan latihan ROM aktif dengan kategori cukup sebanyak 17 orang $(56,7 \%)$ dengan rata-rata $124,43^{\circ}$ di atas $120^{\circ}$, sebagian besar responden rentang gerak sendi ankle kaki gerakan plantar fleksi dengan kategori baik $\left(\geq 50^{\circ}\right)$ sebanyak 17 orang $(56,7 \%)$ dengan rata-rata $48,83^{\circ}$ di atas $45^{\circ}$, dan hampir seluruh responden rentang gerak sendi ankle kaki gerakan dorso fleksi dengan kategori baik $\left(\geq 20^{\circ}\right)$ sebanyak 23 orang (76,7 \%) dengan rata-rata $19,46^{\circ}$ masih di bawah $20^{\circ}$ tetapi ada kenaikan 2,26 dari sebelumnya di Wilayah Kerja Puskesmas Kowel Pamekasan 2020.

Faktor eksternal antara lain suhu tempat latihan, waktu tertentu dalam satu hari, tingkatan dalam proses penyembuhan sendi setelah cedera, usia, jenis kelamin, olah raga, dan keterbatasan karena pakaian atau penggunaan peralatan lain pada sendi. Sendi utama pada ekstremitas bawah terdapat tiga sendi yaitu : untuk melakukan

\section{5| Wiraraja Medika}


split ke depan tidak berarti bisa melakukan split ke samping walaupun kedua aksi tersebut terjadi pada pinggul. Faktor internal yang mempengaruhi fleksibilitas yaitu antara lokasi sendi, kondisi tulang dan kelenturan sistem sendi dan kulit. Kontraksi otot, temperatur dari jaringan sendi dan sekitarnya juga dapat memmengaruhi kelenturan sistem persendian (Chih-Yen, 2017)

\section{Gambaran kekuatan otot kaki sebelum latihan ROM pada lansia.}

Hasil penelitian didapatkan hasil bahwa hampir setengahnya responden kekuatan otot kaki sebelum dilakukan latihan ROM aktif dapat bergerak melawan gravitasi, ROM tidak komplit (fair) sebanyak 17 orang $(56,7 \%)$ dengan rata-rata 3,43 di Wilayah Kerja Puskesmas Kowel Pamekasan 2020.

Perubahan sistem musculoskeletal pada lansia diantaranya serabut otot mengecil menyebabkan kram, pergerakan lamban, tremor, tendon mengerut, dan kekakuan sendi (Aspiani, 2014). Menurut penelitian usia berpengaruh pada kekuatan otot. Perubahan anatomis dan usia menyebabkan atrofi serabut otot sehingga untuk meningkatkan kekuatan otot akan membutuhkan waktu. Semakin jarang lansia menggunakan persendiannya semakin cepat kehilangan kekuatan otot (Stanley \& Beare, 2006). Seiring berkurangnya massa otot, kekuatan otot juga berkurang, sejalan dengan proses penuaan (Potter \& Perry, 2009)

Kemampuan otot sangat berhubungan dengan sistem persyarafan dan otot. Sistem saraf dan otot melakukan kontraksi, menyabakan serat otot yang teraktifasi, dan semakin sering dilakukan maka kekuatan otot juga terjaga. Otot-otot volunter akan kehilangan tonus dan kekuatannya jika tidak digunakan. (Suratun, 2008). Menurut Atmojo, kekuatan otot adalah tenaga kontraksi otot yang dicapai dalam sekali usaha maksimal (Atmojo, 2008). Tenaga kontraksi otot ini dikeluarkan dalam mengatasi tahanan yang diberikan terhadapt otot tersebut (Ismaryati, 2006). Pada lansia, massa dan kekutan otot menurun menyebabkan perubahan morfologis otot sehingga penurunan kekuatan otot, penurunan fleksibilitas, peningkatan waktu reaksi, dan penurunan kemampuan fungsional otot. Jumlah dan ukuran serabut otot mengalami penurunan, jaringan penghubung dan jaringan lemak pada otot meningkat mengakibatkan efek negatif. Untuk mencegah perubahan lebih lanjut dapat diberikan latihan untuk mempertahankan mobilitas (Pudjiastuti \& Utomo, 2003)

\section{Gambaran kekuatan otot kaki sesudah latihan ROM pada lansia.}

Berdasarkan tabel 9 didapatkan hasil bahwa sebagian besar responden kekuatan otot kaki sesudah dilakukan latihan ROM aktif yaitu ROM komplit terhadap gravitasi dengan beberapa resistensi $($ good $=4)$ sebanyak 20 orang $(66,7 \%)$ dengan rata-rata 4,20 di Wilayah Kerja Puskesmas Kowel Pamekasan 2020,

Latihan ROM aktif adalah latihan isotonik. yang menyebabkan otot berkontraksi. Selain itu terjadi perubahan panjang otot dan merangsang aktivitas osteoblastik (aktivitas sel pembentuk otot). Melakukan Latihan ROM aktif secara benar dan rutin akan dapat meningkatkan kekuatan otot, tonus otot serta massa serta mempertahankan fleksibilitas sendi, rentang pergerakan dan sirkulasi (Kozier et al., 2009). Kekuatan otot mengalami penningkatan dipengaruhi oleh jenis latihan, intensitas latihan, dan usia. Semakin sering latihan dilakukan maka persentase peningkatan kekuatan otot akan semakin besar. Kontraksi isotonik menyebabkan kekuatan otot meningkat pada seluruh lingkup gerak sendi. Pemberian latihan penguatan dengan intensitas ringan sampai sedang sudah dapat meningkatkan kekuatan otot secara bermakna pada usia lanjut (Wongkar, 2006).

Bila sebuah otot mulai berkontraksi sesudah lama beristirahat, kekuatan kontraksi permulaannya mungkin separuh kekuatan 10-50 kedutan ototnya kemudian. fenomena tersebut yang disebut efek tangga atau treppe, dimana kekuatan kontraksi meningkat. hingga garis mendatar diduga penyebab utamanya ialah peningkatan ion kalsium dalam sitosol akibat pelepasan ion yang semakin banyak dari retikulum sarkoplasmik pada setiap potensial aksi otot, dan kegagalan untuk menangkap kembali ion-ion dengan segera (Ganong, 2008). Kekuatan otot yang adekuat dari bagian ekstrimitas bawah dapat menyeimbangkan kondisi tubuh ketika berakatifitas. (Dorland, 2002). Kemmapuan otot dalam mengatasi gaya gravitasi mempengaruhi kondisi anatomi tubuh lansia (Wongkar, 2006). Latihan ROM aktif 
merupakan jenis latihan isotonik yang menyebabkan kontraksi otot, perubahan panjangnya otot dan merangsang aktivitas osteoblastik (aktivitas sel pembentuk otot). Latihan ini juga .meningkatkan tonus otot, massa dan kekuatan otot (Potter \& Perry, 2009). Latihan Range of Motion aktif terbukti tidak hanya meningkatkan kekutan otot tetapi juga dapat mempertahankan kekuatan otot. Hal ini terlihat dari hasil penelitian yang menunujukkan bahwa pada rseponden mengalami peningkatan kekuatan otot dari fair menjadi good.

\section{Pengaruh latihan range of motion aktif terhadap peningkatan rentang gerak sendi kaki pada lansia.}

Hasil penelitian data pre test dan post test setelah latihan ROM aktif dengan uji pairet $t$ test didapatkan adanya peningkatan rentang gerak sendi kaki pada Lansia yaitu lutut dengan gerakan fleksi-ekstensi ratarata meningkat sebesar $4,57^{\circ}$ dengan $p$ value 0,000 ( $p$ value $<0,05$ ), maka H0 ditolak, artinya terdapat pengaruh signifikan, ankle dengan gerakan plantar fleksi rata-rata meningkat sebesar $4.53^{\circ}$ dengan $p$ value 0,000 ( $p$ value $<0,05$ ), maka H0 ditolak, artinya terdapat pengaruh signifikan, dan dorsal fleksi rata-rata meningkat sebesar $2.27^{\circ}$ dengan $\mathrm{p}$ value 0,000 ( $\mathrm{p}$ value $<0,05$ ), maka H0 ditolak, artinya terdapat pengaruh signifikan dari latihan ROM aktif terhadap rentang gerak sendi kaki pada Lansia.

Dari hasil penelitian post test diperoleh pengaruh latihan Range of Motion (ROM) aktif terhadap peningkatan rentang gerak sendi pada lansia. Penelitian ini menunjukkan bahwa ada peningkatan yang signifikan antara pengukuran pre-post test. Persendian yang bergerak aktif akan mempengaruhi sistem pembuluh darah pada ektrimitas sehingga nutrisi dan cairan pada persendian dan tulang tercukupi serta nyeri akibat penyakit berkurang (Helmi, 2012). Penelitian lain yaitu oleh Saputra, dalam penelitiannya tentang "Pengaruh latihan ROM terhadap fleksibilitas sendi lutut pada lansia", latihan ROM aktif terbukti tidak hanya meningkatkan rentang gerak tetapi juga dapat mempertahankan rentang gerak (Saputra, 2013). Hasil penelitian ini sejalan dengan penelitian yang menemukan bahwa terdapat peningkatan pada luas rentang gerak sendi lutut maupun ankle setelah di lakukan latihan ROM aktif selama 2 minggu dengan frekuensi 5 kali sehari. Pada analisis lebih lanjut di dapatkan $\mathrm{p}$ value sebesar 0,030 untuk luas rentang gerak sendi lutut kiri dan 0,023 untuk sendi lutut kanan ( $p$ value $<0,05$ ). Hasil penelitian ini menunjukkan bahwa ada pengaruh signifikan latihan ROM aktif terhadap peningkatan rentang gerak sendi lutut kaki (Sucipto, 2015).

\section{Pengaruh latihan Range Of Motion aktif terhadap kekuatan otot kaki pada lansia.}

Pada pengukuran kekuatan otok kaki sesudah latihan ROM aktif, didapatkan peningkatan rata-rata sebesar 0,76 dan terdapat pengaruh signifikan. Hasil penelitian lain menemukan bahwa terdapat peningkatan kekuatan otot setelah dilakukan ROM aktif. Latihan ini menjaga kondisi anatomis otot dan meningkatkan aktifitas pembentul sel otot pada lansia (Mudrikhah, 2012). Sehingga apabila latihan tersebut dilakukan secara rutin dan konsisten makan dapat mempertahankan kondisi sendi dan otot serta menjaga fleksibilitasnya (Kozier et al., 2009).

Hasil penelitian ini sesuai dengan penelitian Safaah, penelitian ini menunjukkan bahwa latihan Range of Motion aktif merupakan salah satu latihan yang efektif terhadap peningkatan kekuatan otot pada lansia, khususnya lansia dengan penyakit degenerative osteoarthritis (Mudrikhah, 2012). Tidak hanya itu latihan ini juga bermanfaat dilakukan untuk lansia lainnya, dengan gerakan yang mudah dan dapat dilakukan secara mandiri dirumah. Sehingga perlu adanya upaya bagi pihak terkait untuk dapat membuat suatu program latihan Range Of Motion (ROM) aktif baik secara individual maupun secara berkelompok. (Ambartana, 2010)

Menurut peneliti, dari pengertian diatas dapat disimpulkan bahwa latihan ROM aktif sangat bermanfaat bagi lansia terlebih lagi lansia dengan penyakit degeneratif seperti osteoarthritis. Seperti yang. dikemukakan Stanley \& Beare dengan pemeliharaan kekuatan otot dan fleksibilitas sendi, latihan Range of Motion $(R O M)$ bisa meningkatkan dan mempertahankan kekuatan otot dan fleksibilitas sendi karena dari 10 sampai 15\% kekuatan otot dapat hilang setiap minggu jika otot beristirahat sepenuhnya, dan sebanyak 5,5\% dapat hilang setiap hari pada kondisi istirahat dan imobilitas 
sepenuhnya (Stanley \& Beare, 2006). Kekuatan otot dipengaruhi oleh latihan dan umur. Peningkatan secara bertahap terhadap intensitas latihan menyebabkan peningkatan kekuatan otot dan sendi bagi lansia.

\section{Pengaruh latihan range of motion aktif terhadap peningkatan rentang gerak sendi kaki dan kekuatan otot pada lansia.}

Luas gerak sendi dan kekuatan otot kaki dengan latihan rangen of motion (ROM) aktif dapat meningkatkan sirkulasi darah. Menurut Sucipto menyatakan bahwa adanya pergerakan pada persendian akan menyebabkan terjadinya peningkatan aliran darah ke. dalam kapsul sendi. Sendi lutut yang digerakkan berdampak pada permukaan kartilago antara .kedua tulang saling bergesekan (Sucipto, 2015). Studi tentang efektifitas latihan gerak aktif yang dilakukan oleh feland dkk menyebutkan dengan latihan selama 6 minggu dapat meningkatkan kondisi sistem persendian pada lansia (Safa'ah, 2013). Bagi yang mengalami permasalahan pada sistem persendian minimal dilakukan ROM aktif selama 3 minggu (Uliya et al., 2007).

\section{Simpulan}

Sebagian besar responden mempunyai luas Gerak Sendi lutut gerakan fleksi-ekstensi dengan kategori kurang, hampir setengah responden memiliki rentang gerak sendi ankle kaki gerakan plantar fleksi dengan kategori kurang, dan sebagian besar responden memiliki rentang gerak sendi ankle kaki gerakan dorso fleksi dengan kategori cukup sebelum dilakukan latihan ROM aktif. Sebagian besar responden memiliki Luas Gerak Sendi lutut kaki gerakan fleksi-ekstensi dengan kategori cukup, sebagian besar rentang gerak sendi ankle kaki gerakan plantar fleksi dengan kategori baik dan hampir seluruhnya rentang gerak sendi ankle kaki gerakan dorso fleksi dengan kategori baik sesudah dilakukan latihan ROM aktif. Hampir setengah responden memiliki kekuatan otot kaki dapat bergerak melawan gravitasi, ROM tidak komplit (fair) sebelum dilakukan latihan ROM aktif. Sebagian besar responden memiliki kekuatan otot kaki ROM komplit terhadap gravitasi dengan beberapa resistensi $($ good $=4)$ sesudah dilakukan latihan ROM aktif. Ada pengaruh yang signifikan latihan ROM aktif terhadap peningkatan luas gerak sendi lutut kaki pada Lansia . Ada pengaruh yang signifikan latihan ROM aktif terhadap peningkatan luas gerak sendi ankle kaki pada Lansia . Ada pengaruh yang signifikan latihan ROM aktif terhadap peningkatan kekuatan otot kaki pada Lansia. Ada pengaruh yang signifikan latihan ROM aktif terhadap peningkatan luas gerak sendi dan kekuatan otot kaki pada Lansia

\section{Referensi}

Ambartana, W. I. (2010). Hubungan Status Gizi Dengan Kekuatan Otot Lanjut Usia Di Kelurahan Gianyar, Kabupaten Gianyar Provinsi Bali. JIG, 1, 67 - 74.

Aspiani, Y. R. (2014). Buku Ajar Asuhan Keperawatan Gerontik. Trans Info Media.

Atmojo, M. . (2008). Tes \& Pengukuran Pendidikan Jasmani/ Olahraga. Lembaga Pengembangan Pendidikan (LPP) UNS.

Ayu, A. D., \& Warsito B. E. (2014). Pemberian Intervensi Senam Lansia Pada Lansia Dengan Nyeri Lutut. Jurnal Nursing Studies, 1, 60-65.

Chih-Yen, C. (2017). Data Collection and Analysis Using Wearable Sensors for Monitoring Knee Range of Motion after Total Knee Arthroplasty. Sensors, $17,418$. https://doi.org/doi:10.3390/s1702041 8

Dorland, W. (2002). Kamus Kedokteran Dorland (Edisi Kedua puluh sembilan). Penerbit Buku Kedokteran.

Ganong, W. (2008). Jaringan Peka Rangsang: Otot. Buku Ajar Fisiologi Kedokteran (Edisi Keduapuluhdua). EGC.

Helmi, N. Z. (2012). Buku Ajar Gangguan Muskuloskeletal. Salemba Medika.

Hetty, A. G. (2020). Lansia, Pandemi, dan "New Normal"., Dosen FISIP Universitas Pelita Harapan., Jumat, 19 Juni 2020 / 08:00 WIB.

Ismaryati. (2006). Tes Dan Pengukuran Olahraga. Sebelas Maret University Perss.

Kozier, B., Erb, G., Berman, A., \& Snyder, S. (2009). Buku Ajar Praktek Keperawatan Klinis (5th ed.). EGC.

Mudrikhah. (2012). Pengaruh Latihan Range Of Motion Aktif Terhadap Peningkatan 
Rentang Gerak Sendi Dan Kekuatan Otot Kaki Pada Lanjut Usia Di Panti Werda Dharma Bakti Surakarta. Jurnal Keperawatan Fakultas Ilmu Kesehatan Universitas Muhammadiyah Surakarta, 3, 54-57.

Nainggolan, O. (2009). Prevalensi dan Determinan Penyakit Rematik di Indonesia. Artikel Penelitian, 12, 588 594.

Nasir, A., Abdul, M., \& Ideputeri. (2011). Buku Ajar Metodologi Penelitian Kesehatan. Konsep Pembuatan Karya Iliah dan Thesis untuk Mahasiswa Kesehatan. Penerbit Nuha Medika.

Padila. (2013). Buku Ajar KeperawatanGerontik. Nuha Medika.

Potter, P., \& Perry, A. G. (2009). Fundamental Keperawatan. Buku 1 edisi ke-7 (Adrina Ferderika \& Marina Albar, Penerjemah). Salemba Medika.

Pudjiastuti, S., \& Utomo, B. (2003). Fisioterapi Pada Lansia. EGC.

Reveese, N. (2009). Joint Range of Motion and Muscle Length Testing (II). Elsevier Health Sciences.

Safa'ah, N. (2013). Pengaruh Latihan Range Of Motion Terhadap Peningkatan Kekuatan Otot Lanjut Usia di UPT Pelayanan Sosial Lanjut Usia (Pasuruan) Kec. Babat Kab. Lamongan. Jurnal SainMed, 2, 62-65.

Saputra, L. (2013). Pengantar Kebutuhan Dasar Manusia. Binapura Aksara Publisher.

Stanley, M., \& Beare, G. P. (2006). Buku Ajar KeperawatanGerontik(Edisi 2). EGC.

Sucipto, E. (2015). Pengaruh Latihan ROM aktif terahap Luas Gerak Sendi tungkai pada Lansia di Wilayah Kerja Puskesmas global telaga Kabupaten Gorontalo.

Suhendriyo. (2014). Pengaruh senam rematik terhadap pengurangan rasa nyeri pada penderita osteoarthritis lutut di Karangasem, Surakarta. Jurnal Terpadu Ilmu Kesehatan, 1, 1-6.

Suratun. (2008). Klien Gangguan Sistem Muskuloskeletal. EGC.

Uliya, S., Soempeno, B., \& B.M.W.Kushartanti. (2007). Pengaruh Latihan Range Of Motion (ROM) Terhadap Fleksibilitas Sendi Lutut Pada Lansia Di Panti Wreda Wening Wardoyo Ungaran. Jurnal Media Ners, 1(2), 72-78.

Wongkar, D. (2006). Ekstremitas Inferior. Manado: Bagian Anatomi Histologi
Fakultas Kedokteran Universitas Sam Ratulangi.

\section{9| Wiraraja Medika}

